\title{
Carbohydrate Binding Studies on the Lectin from Datura stramonium Seeds ${ }^{1}$
}

\author{
JANE F. CROWLEY, IRWIN J. GOLDSTEIN, ${ }^{2}$ JAN ARNARP,* \\ AND JÖRGEN LÖNNGREN* \\ Department of Biological Chemistry, University of Michigan, Ann Arbor, Michigan 48109, and \\ *Department of Organic Chemistry, University of Sweden, S-106 91 Stockholm, Sweden
}

Received December 7, 1983, and in revised form February 21, 1984

The carbohydrate-binding properties of the Datura stramonium seed lectin were studied by equilibrium dialysis, quantitative precipitation of natural and synthetic glycoproteins, and hapten inhibition of precipitation. The dimeric lectin $\left(M_{\mathrm{r}}=86,000\right)$ possesses two carbohydrate-binding sites for $N, N^{\prime}, N^{\prime \prime}, N^{\prime \prime \prime}$-tetraacetylchitotetritol/mol protein, with an apparent $K_{a}=8.7 \times 10^{3} \mathrm{M}^{-1}$ at $4^{\circ} \mathrm{C}$. Whereas fetuin and orosomucoid reacted poorly with the Datura lectin, the asialo derivatives of these glycoproteins gave strong precipitation with the lectin. Carcinoembryonic antigen, type 14 pneumococcal capsular polysaccharide, and bovine serum albumin, highly substituted with $N, N^{\prime}-$ diacetylchitobiose units, also precipitated the lectin. Of the homologous series of chitin oligosaccharides tested, $N, N^{\prime}, N^{\prime \prime \prime}$-triacetylchitotriose was over 6 -fold more potent than the disaccharide ( $N, N^{\prime}$-diacetylchitobiose) which, in turn, was 90 times more reactive than $N$-acetyl-D-glucosamine. $N$-Acetyllactosamine [ $\beta$-D-Gal- $(1 \rightarrow 4)$-D-GlcNAc] was also a potent inhibitor of Datura lectin being equivalent to $N, N^{\prime}$-diacetylchitobiose. The requirement for an $N$-acetyl-D-glucosaminyl unit linked at the $\mathrm{C}-4$ position was established. The biantennary pentasaccharide (penta-2,6) was a 500-fold more potent inhibitor than $\mathrm{N}$-acetyllactosamine, suggesting that it might interact with both saccharide-binding sites of the Datura lectin simultancously.

The seeds of Datura stramonium (jimson weed or thorn apple) contain a lectin which specifically binds $\beta$ - $(1 \rightarrow 4)$-linked oligomers of $N$-acetyl-D-glucosamine $(1,2)$. It has been partially purified by affinity chromatography on fetuin-Sepharose (3), ovomucoid-Sepharose (4), glutaraldehydefixed erythrocytes $(5,6)$, and on an insoluble polysaccharide mixture from Aspergillus niger mycelia (7). A recent report from this laboratory (8) described the purification of the Datura lectin on an $N, N^{\prime}$ diacetyl- $\beta$-chitobioside-Sepharose column.

\footnotetext{
${ }^{1}$ This study was supported by Public Health Service Grant GM 29470 fron the National Institutes of Health.

${ }^{2}$ To whom correspondence should be addressed.
}

The purified lectin appeared homogeneous by sedimentation analysis, gel filtration, electrophoresis under both native and denaturing conditions, and immunoelectrophoresis; the 32,000-d protein which has contaminated all previously reported lectin preparations was not detected. The Datura lectin, a dimeric glycoprotein composed of two nonidentical subunits $\left(M_{\mathrm{r}} 40,000\right.$ and $46,000)$ joined by disulfide bonds $(3,4,8$, 9 ), contains $37 \%$ carbohydrate by weight, of which $93 \%$ is arabinose and $7 \%$ is galactose $(4,8,9)$.

In this communication, we report on the carbohydrate-binding specificity of Datura lectin. The physicochemical and biological properties of the lectin will be described in a separate communication. 


\section{MATERIALS AND METHODS}

Sugars and sugar derivatives. $p$-Nitrophenyl $N, N^{\prime}$ diacetyl- $\beta$-chitobioside and $p$-nitrophenyl $N, N^{\prime}, N^{\prime \prime}-$ triacetyl- $\beta$-chitotrioside were synthesized by the method of Osawa (10). $p$-Nitrophenyl- $\alpha$-D-GleNAc $p^{3}$ was purchased from Vega Biochemicals, Tucson, Arizona; $p$-nitrophenyl- $\beta-\mathrm{D}-\mathrm{Gal} p$ was purchased from Koch-Light Laboratories, Colnbrook Bucks, England. $p$-Nitrophenyl $\beta-\mathrm{D}$-GlcNAc $p$ was available in this laboratory from previous studies. Per- $N$-acetylated chitobiose and chitotriose were prepared in this laboratory by acetolysis of chitin (11) by Dr, R. Kaifu. The corresponding 1-chloro- and $\beta$-methyl- derivatives were synthesized according to the method of Dahlquist and Raftery (12). Methyl $\beta$-chitobioside octaacetate was $O$ - and $N$-deacetylated by treatment with anhydrous hydrazine at $100^{\circ} \mathrm{C}$ for $72 \mathrm{~h} \mathrm{(13)}$. The chitobioside was reacted with $S$-ethyltrifluorothioacetate (14) to afford methyl $N, N^{\prime}$-ditrifluoroacetyl- $\beta$-chitobioside. Reaction of the chitobioside with propionic anhydride (Kaifu et al, submitted) gave methyl $N, N^{\prime}-$ dipropionyl- $\beta$-chitobioside. Heptaacetylchitobiose hydrochloride was synthesized as described by Dahlquist et $a l$. (12), and de- $O$-acetylated with sodium methoxide to give $\beta$-D-GleNAc- $(1 \longrightarrow 4)$-D-GleN. Treatment of this disaccharide with S-ethyltrifluorothioacetate or propionic anhydride, as described above, gave $N$-trifluoroacetyl, $N^{\prime}$-acetylchitobiose, and $N$-propionyl, $N^{\prime}$-acetylchitobiose, respectively. $\mathrm{Re}-$ action of heptaacetylchitobiose hydrochloride with benzoyl chloride in pyridine (Kaifu et al., submitted), followed by de- $O$-acetylation, gave $N$-benzoyl, $N^{\prime}$-acetylchitobiose. Dr. R. Spiro, Harvard University, donated $\beta$-D-Man- $(1 \rightarrow 4)-D-G l c N A c$ and $\beta$-D-GlcNAc$(1 \rightarrow 6)-D-G a l$. Dr. G. W. Jourdian of this University provided $\beta$-D-GlcNAc $(1 \rightarrow N)$ Asn. The following synthetic oligosaccharides, the structures of which are shown in Fig. 4, were provided by Arnarp and Lönngren (15-18): hepta; penta-2,6; penta-2,4; tri-2,6; tri$2,4 ; \beta$-D-Gal-(1 $\rightarrow 4)$ - $\beta$-D-GlcNAc- $(1 \rightarrow 2)$-U-Man; $\beta$ $\mathrm{D}-\mathrm{Gal}-(1 \rightarrow 4)-\beta$-D-GlcNAc- $(1 \rightarrow 6)$-D-Man; nona $\mathrm{I}$; nona II; undeca; Hexa-3,6; and aryl penta-2,6. $N$-Acetyllactosamine [ $\beta-\nu-G a l-(1 \rightarrow 4)-\nu-G l c N A c], \beta-D-$ GlcNAc- $(1 \rightarrow 6)$-D-Gal, 4- $O$-methyl-D-GlcNAc, and methyl 3-O-methyl $\beta$-D-GlcNAc $p$ were synthesized by Nike Plessas of this laboratory. Methyl $\beta-D-G l c N A c p$ and 3,6-di- $O$ - $(\beta$-D-GlcNAc $p)-\mathrm{D}-\mathrm{Gal} p$ were available in this laboratory from previous studies.

Glycoproteins and polysaccharides. D. stramonium seeds were obtained from the Matthaei Botanical Gardens, University of Michigan. Datura lectin was purified according to the method described previously

\footnotetext{
${ }^{3}$ Abbreviations used: GleNAcp, N-acetylglucosamine pyranose; GlcN, glucosamine; PBS, phosphatebuffered saline; BSA, bovine serum albumin.
}

(8). Carcinoembryonic antigen, S-14 pneumococcal polysaccharide, and orosomucoid were available in this laboratory from previous studies. Fetuin was purchased from Gibco, Grand Island, New York.

Sialic acid was selectively removed from fetuin and orosomucoid by treatment at $80^{\circ} \mathrm{C}$ for $1 \mathrm{~h}$ in $0.1 \mathrm{~N}$ sulfuric acid (19). Desialation was determined using the thiobarbituric acid assay of Warren (20). The pentultimate galactose residues was removed by treatment of the asialoglycoprotein with bovine testicular $\beta$-galactosidase, prepared by Diane Blake in this laboratory according to the method of Distler et $a l$, (21). The glycoprotein was incubated with $\beta$-galactosidase $(1 / 2$ unit $/ \mathrm{ml}$ reaction volume) in $0.1 \mathrm{M}$ citrate buffer, $\mathrm{pH} 4.5$, for $6 \mathrm{~h}$ at $37^{\circ} \mathrm{C}$. An aliquot of the reaction mixture was analyzed for free galactose using a galactose dehydrogenase assay (22). The $\beta$ galactosidase was removed by applying the reaction mixture to an affinity matrix of agarose- $\beta$-1-thiogalactoside obtained from Dr. Jourdian of this Department. The $\beta$-galactosidase binds to the matrix at pH 5, and can be eluted at pH 7.5.

Precipitin and hapten inhibition reactions. Precipitin reactions were conducted as described by So and Goldstein (23) using $27 \mu \mathrm{g}$ Datura lectin and varying amounts of glycoconjugate per tube. Total volume was brought to $0.5 \mathrm{ml}$ with PBS. Sugar inhibition of the precipitin reaction was conducted by adding increasing amounts of carbohydrate hapten to the tubes containing Datura lectin (27 $\mu \mathrm{g})$ in PBS. After a 10min preincubation period, the precipitin reaction was initiated by addition of asialofetuin $(80 \mu \mathrm{g})$ to give a final volume of $0.5 \mathrm{ml}$. The inhibition curve of $N, N^{\prime}-$ diacetylchitobiose was routinely run as a standard.

Equilibrium dialysis. Radioactive ligand was obtained by reduction of $N, N^{\prime}, N^{\prime \prime}, N^{\prime \prime \prime}$-tetraacetylchitotetraose with $\left[{ }^{3} \mathrm{H}\right]$ borohydride. Equilibrium dialysis experiments were performed in duplicate in a multichambered dialysis cell (Seientific Specialties, Inc., Randallstown, Md.). Lectin concentration was $21 \mu \mathrm{M}$ and initial ligand concentrations varied from $50 \mu \mathrm{M}$ to $1 \mathrm{mM}$. Filled dialysis cells, each containing $350 \mu \mathrm{l}$ solution, were slowly rotated for $48 \mathrm{~h}$ at $4^{\circ} \mathrm{C}$. Upon reaching equilibrium, aliquots $(40 \mu \mathrm{l})$ were removed and counted in ACS counting scintillant (Amersham Corp., Arlington Heights, Ill.). It was necessary to add an additional $200 \mu \mathrm{l}$ water to each scintillation vial prior to counting in order to stabilize the counts.

\section{RESULTS}

A Scatchard plot of the binding of $\left[{ }^{3} \mathrm{H}\right] N, N^{\prime}, N^{\prime \prime}, N^{\prime \prime \prime}$-tetraacetylchitotetritol to Datura lectin at $4^{\circ} \mathrm{C}$ is shown in Fig. 1 . The absence of curvature in the plot suggests that the sugar-binding sites are noninteracting and homogeneous with respect to association constant. Assuming a mo- 


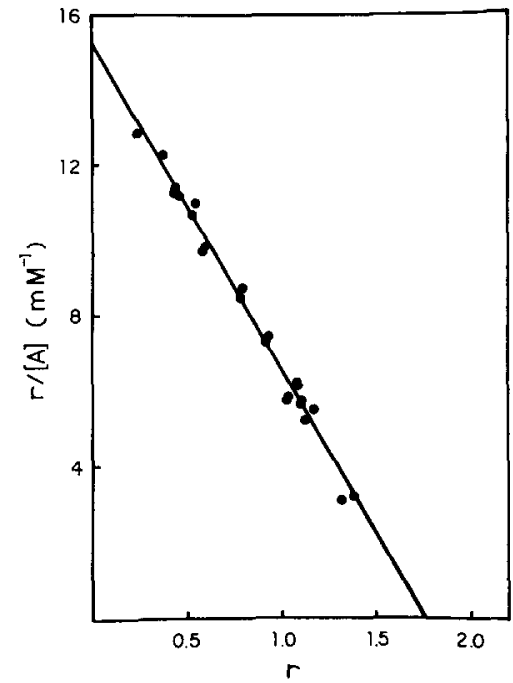

FIG. 1. Binding of $\left[{ }^{3} \mathrm{H}\right]-N, N^{\prime}, N^{\prime \prime}, N^{\prime \prime \prime}$-tetraacetylchitotetritol to Datura lectin plotted according to Scatchard. [A], concentration of free sugar; $r$, moles of sugar bound per mole lectin. Lectin concentration was $21 \mu \mathrm{M}$ and initial ligand concentrations varied from $50 \mu \mathrm{M}$ to $1 \mathrm{mM}$. Binding was performed at $4^{\circ} \mathrm{C}$ for $48 \mathrm{~h}$.

lecular weight of 86,000 , these data indicate that the dimeric lectin can bind $2 \mathrm{~mol}$ of sugar per mol protein, with an apparent association constant of $8.7 \times 10^{3} \mathrm{M}^{-1}$.

A number of glycoproteins and glycoconjugates containing terminal and/or internal $N$-acetyl-D-glucosamine residues were examined for their ability to form a precipitate with the Datura lectin. The lectin did not precipitate any synthetic glycoconjugates in which simple monosaccharides had been linked to bovine serum albumin (BSA). It did react with $p$-azophenyl $N, N^{\prime}$-diacetyl- $\beta$-chitobioside-BSA, but only if the degree of substitution on BSA was high. A sample containing 5 disaccharide units per mol BSA was not precipitated by Datura lectin, whereas a sample with 17 residues per mol BSA did form a precipitate. By contrast, wheat germ agglutinin and potato lectin were able to precipitate both samples. Shier's antigen A (24), which contains $N, N^{\prime}$-diacetylchitobiose glycosidically linked to poly-L-asparatate via asparaginyl bonds, did not precipitate the Datura lectin, presumably because of the low degree of substitution
(13\%). Other biopolymers found to be nonreactive with Datura lectin include ethylene glycol chitin, a soluble derivative of chitin in which some of the C-6 hydroxyl groups had been modified to the corresponding hydroxyethyl ethers; keratan sulfate, which is composed of repeating units of 3$)-\beta$-D-galactosyl- $(1 \rightarrow 4)-\beta-N$-acetyl-D-glucosamine-6-sulfate- $(1 \rightarrow$; and $\beta$-DGleNAc- $(1 \rightarrow 6)$-D-Gal-BSA (21 residues/ mol BSA).

Several glycoproteins containing internal $N$-acetyl-D-glucosamine residues were shown to precipitate with Datura lectin. rcinoembryonic antigen (CEA), a tumorassociated antigen composed of $50 \%$ carbohydrate of which a high proportion are $\beta$ - $(1 \rightarrow 4)$ linked $N$-acetyl-D-glucosamine residues (25), reacted strongly with Datura lectin. Pneumococcus type 14 capsular polysaccharide, which consists of tetrasaccharide repeating units of the form (26),

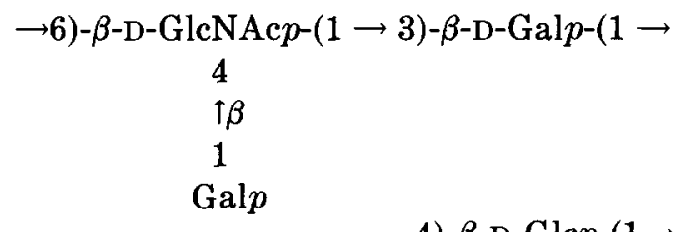

also reacted strongly with Datura lectin.

The reactivity of Datura lectin with fetuin and orosomucoid, and their asialo and asialoagalacto analogs, is shown in Fig. 2. Fetuin and orosomucoid were subjected to mild acid hydrolysis, resulting in liberation of 92 and $93 \%$ of the sialic acid, respectively. Subsequent treatment of the asialoproteins with bovine testicular $\beta$-galactosidase resulted in removal of 93 and $78 \%$ of the galactosyl residues from fetuin and orosomucoid, respectively. Datura lectin reacted only weakly with both fetuin and orosomucoid. Desialation of the parent glycoproteins rendered them much more reactive towards precipitation with Datura lectin. It is apparent from these results that the presence of sialic acid interferes with the precipitation. This could be due to steric interference and/or nonspecific charge effects.

Removal of the galactosyl residues from asialofetuin resulted in a $50 \%$ decrease in 


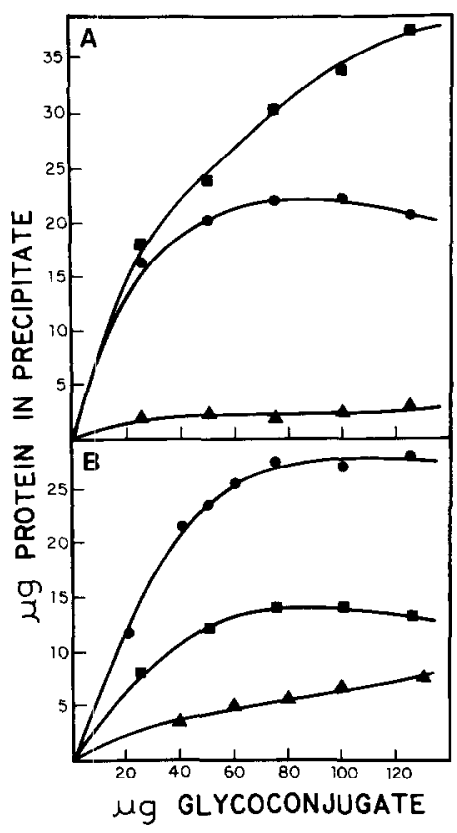

FIG. 2. Quantitative precipitation of fetuin, orosomucoid (OSM), and their analogs by Datura lectin. Each tube contained $27 \mu \mathrm{g}$ lectin and increasing amounts of glycoprotein in a total volume of $500 \mu \mathrm{l}$. (A) OSM (४); asialo-OSM (๑); asialo-agalacto-OSM (Ф); (B) fetuin (A); asialofetuin (๑); asialo-agalactofetuin (a).

precipitated protein. Removal of the galactosyl residues from asialoorosomucoid, however, increased the reactivity towards
Datura lectin (Fig. 2). The reason for the differential reactivity of the asialoagalacto-glycoproteins towards Datura lectin is uncertain. Although both fetuin and orosomucoid are $\mathrm{N}$-acetyllactosamine-type glycans, there are structural differences in their carbohydrate moieties. It may be that Datura lectin can bind terminal, nonreducing $N$-acetyl-D-glucosamine residues only if there is a high density of such residues near the binding sites, as has been suggested by Debray et al. (27). The presence of $L$-fucose in the carbohydrate structure of orosomucoid may also play a role in the interactions with Datura lectin.

\section{Inhibition of Datura Lectin-Asialofetuin Interaction by Low-Molecular- Weight Sugars}

The carbohydrate-binding specificity of the Datura lectin was probed by sugar inhibition of the lectin-asialofetuin precipitation system. When plotted as percentage inhibition versus the inhibitor concentration on a logarithmic scale, typical sigmoidal inhibition curves were obtained (Fig. 3). The inhibitors tested, and the concentrations required for $50 \%$ inhibition by each hapten, are listed in Tables I and II.

As was originally noted by Pardoe et al. (2), Datura lectin displays a general spec-

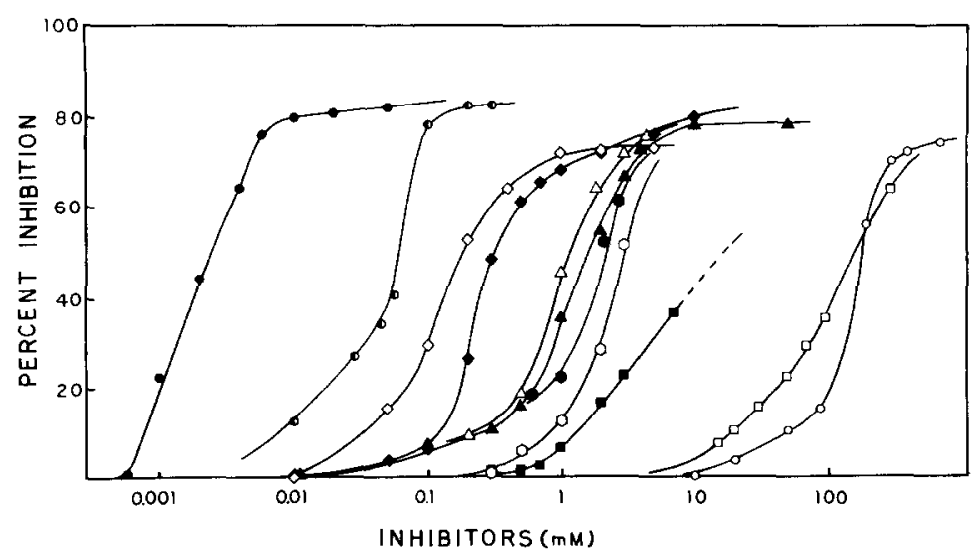

FIG. 3. Inhibition of Datura lectin-asialofetuin precipitation reaction by low-molecular-weight sugars. Conditions are stated under Material and Methods. $\bullet$, Penta-2,6; 0 , Penta-2,4; $\hat{\vee}, N, N^{\prime \prime}, N^{\prime \prime}, N^{\prime \prime \prime}$ tetraacetylchitotetraose; $\bullet, N, N^{\prime}, N^{\prime \prime}$-triacetylchitotriose; $\Delta, N$-acetyllactosamine; $\Delta, N, N^{\prime}$-diacetylchitobiose; $\bullet, \beta$-Gal-(1 $\rightarrow$ 4)- $\beta$-GlcNAc- $(1 \rightarrow 6)$-Man; $0, \beta$-Man $(1 \rightarrow 4)$-GlcNAc; $\square, \beta$-Gal- $(1 \rightarrow$ 4)- $\beta$-GlcNAc- $(1 \rightarrow 2)$-Man; $\square, \beta$-GlcNAc- $(1 \rightarrow 6)$-Gal; $O$, $N$-acetyl-L-glucosamine. 
TABLE I

Inhibition of Datura Lectin-Asialofetuin Precipitation by Low Molectlar Weight Sugars

\begin{tabular}{|c|c|c|c|}
\hline Sugar & $\begin{array}{c}\text { [I]mM required } \\
\text { for } 50 \% \\
\text { inhibition }\end{array}$ & Sugar & $\begin{array}{c}\text { [I]mm required } \\
\text { for } 50 \% \\
\text { inhibition }\end{array}$ \\
\hline$N$-Acetyl-D-Glucosamine & 180 & $\beta$-D-Gal- $(1 \rightarrow 4)-\beta$-D-GleNAc- & \\
\hline$N, N^{\prime}$-Diacetylchitobiose & 2.0 & $(1 \rightarrow 6)-D-M a n$ & 2.0 \\
\hline$N, N^{\prime}, N^{\prime \prime}$-Triacetylchitotriose & 0.32 & $\beta$-D-Gal- $(1 \rightarrow 4)-\beta-\mathrm{D}-\mathrm{GlcNAc}$ & \\
\hline$N, N^{\prime}, N^{\prime \prime}, N^{\prime \prime \prime}-$ & & $(1 \rightarrow 2)-D-M a n$ & 16.0 \\
\hline Tetraacetylchitotetraose & 0.18 & $p$-Nitrophenyl $(\beta$-D-Gal- $(1 \rightarrow 4)-\beta-$ & \\
\hline$N, N^{\prime}$-Diacetylchitobiitol & $0 \%, 8 \mathrm{~mm}$ & D-GleNAc- $(1 \rightarrow 2)-\beta-\mathrm{D}-\mathrm{Man} p$ & 35.0 \\
\hline$N, N^{\prime}, N^{\prime \prime}$-Triacetylchitotriitol & 3.5 & $\beta$-D-Gal $(1 \rightarrow 4)-\mathrm{D}-\mathrm{Glc}$ & $0 \%, 200 \mathrm{~mm}$ \\
\hline$N, N^{\prime}, N^{\prime \prime}, N^{\prime \prime}-$ & & $\beta$-D-Glc- $(1 \rightarrow 4)-\mathrm{D}-\mathrm{Glc}$ & $0 \%, 200 \mathrm{~mm}$ \\
\hline Tetraacetylchitotetritol & 0.38 & $\beta$-D-GlcNAc- $(1 \rightarrow 4)$-D-Gln & 4.6 \\
\hline $\begin{array}{l}\text { Methyl } N \text {-acetyl- } \beta \text {-D- } \\
\text { glucosaminide }\end{array}$ & $13 \%, 40 \mathrm{mM}$ & $\begin{array}{l}\beta \text {-D-GlcNAc- }(1 \rightarrow 4) \text {-D-Glc } \\
N \text {-Trifluoroacetyl, } N^{\prime}-\end{array}$ & 85 \\
\hline $\begin{array}{l}\text { Methyl } N, N^{\prime} \text {-diacetyl- } \beta \text { - } \\
\text { chitobioside }\end{array}$ & 1.3 & $\begin{array}{l}\text { acetylchitobiose } \\
N \text {-Propionyl, } N^{\prime} \text {-acetylchitobiose }\end{array}$ & $\begin{array}{l}2.5 \\
2.4\end{array}$ \\
\hline $\begin{array}{l}\text { Methyl } N, N^{\prime}, N^{\prime \prime} \text {-triacetyl- } \beta \text { - } \\
\text { chitotrioside }\end{array}$ & 0.38 & $\begin{array}{l}N \text {-Benzoyl, } N^{\prime} \text {-acetylchitobiose } \\
\text { Methyl } N, N^{\prime} \text {-ditrifluoroacetyl- } \beta \text { - }\end{array}$ & $0 \%, 4 \mathrm{mM}$ \\
\hline $\begin{array}{l}p \text {-Nitrophenyl } N \text {-acetyl- } \beta \text {-D- } \\
\text { glucosaminide }\end{array}$ & 9.0 & $\begin{array}{l}\text { chitobioside } \\
\text { Methyl } N, N^{\prime} \text {-dipropionyl- } \beta \text { - }\end{array}$ & 4.7 \\
\hline $\begin{array}{l}p \text {-Nitrophenyl } N, N^{\prime} \text {-diacetyl- } \beta \text { - } \\
\text { chitobioside }\end{array}$ & 0.2 & $\begin{array}{l}\text { chitobioside } \\
\text { Chitobiose }\end{array}$ & $\begin{array}{c}5.6 \\
0 \%, 12 \mathrm{mM}\end{array}$ \\
\hline $\begin{array}{l}p \text {-Nitrophenyl } N, N^{\prime}, N^{\prime \prime} \text {-triacetyl- } \beta \text { - } \\
\text { chitotrioside }\end{array}$ & 0.24 & $\begin{array}{l}\beta \text {-D-GlcNAc- }(1 \rightarrow 6) \text {-D-Gal } \\
\beta \text {-D-Gal- }(1 \rightarrow 6) \text {-D-GlcNAc }\end{array}$ & $\begin{array}{l}170 \\
0 \%, 32 \mathrm{mM}\end{array}$ \\
\hline $\begin{array}{l}p \text {-Nitrophenyl } N \text {-acetyl- } \alpha-\mathrm{D}^{-} \\
\text {glucosaminide }\end{array}$ & 11.0 & $\begin{array}{l}\text { 3,6-di-O-( } \beta \text {-D-GlcNAc)-D-Gal } \\
2,6-\text { di-O-( } \beta \text {-D-GlcNAc)-D-Man }\end{array}$ & $\begin{array}{l}0 \%, 13 \mathrm{mM} \\
0 \%, 3 \mathrm{mM}\end{array}$ \\
\hline$p$-Nitrophenyl $\beta$-D-galactoside & $0 \%, 8 \mathrm{~mm}$ & $2,4 \mathrm{di}-O-(\beta-\mathrm{D}-\mathrm{GlcNAc})-\mathrm{D}-\mathrm{Man}$ & $0 \%, 3 \mathrm{~mm}$ \\
\hline$\beta$-D-Gal-(1 $\rightarrow 4)-\mathrm{D}-\mathrm{GlcNAc}$ & 1.2 & $\beta$-D-GlcNAc- $(1-N)$ Asn & $0 \%, 12 \mathrm{~mm}$ \\
\hline$\beta$-D-Gal- $(1 \rightarrow 4)-\mathrm{D}-\mathrm{ManNAc}$ & $28 \%, 50 \mathrm{mM}$ & Methyl 3-O-methyl- $\beta$-D-GlcNAcp & $17 \%, 50 \mathrm{mM}$ \\
\hline Me $\beta$-D-Gal- $(1 \rightarrow 4)-\beta$-D-GleN & 70.0 & 4-O-methyl-D-GlcNAc & $11 \%, 50 \mathrm{mM}$ \\
\hline Me $\beta$-D-Gal- $(1 \rightarrow 4)-\beta$-D-GleNProp & 6.2 & Penta-2, $4^{a}$ & 0.065 \\
\hline$\beta$-D-Man $(1 \rightarrow 4)-\mathrm{D}-\mathrm{GlcNAc}$ & 3.0 & Penta-2, $6^{a}$ & 0.0025 \\
\hline $\begin{array}{l}\alpha-\mathrm{D}-\mathrm{Man}-(1 \rightarrow 3)-\beta-\mathrm{D}-\mathrm{Man}(1 \rightarrow 4)- \\
\quad \text { D-GlcNAc }\end{array}$ & 2.1 & Hepta $^{a}$ & 0.45 \\
\hline
\end{tabular}

${ }^{a}$ Structures shown in Fig. 4.

TABLE II

INHIBITION OF DATURA LeCtin-AsialofETUIN Precipitation by Oligosaccharides

\begin{tabular}{lc}
\multicolumn{1}{c}{ Sugar ${ }^{a}$} & $\begin{array}{c}{[\mathrm{I}] \mu \mathrm{M} \text { required }} \\
\text { for } 50 \% \text { inhibition }\end{array}$ \\
\hline Penta-2,6 & 2.5 \\
Nona II & 4.6 \\
Aryl Penta-2,6 & 6.2 \\
Undeca & 6.4 \\
Penta-2,4 & 64 \\
Nona I & 120 \\
Hexa-3,6 & 110 \\
Hepta & 450 \\
\hline
\end{tabular}

${ }^{a}$ Structures shown in Fig. 4. ificity for $\beta-(1 \rightarrow 4)$ linked oligomers of $N$ acetyl-D-glucosamine. The values given in Table I for the per- $N$-acetylated chitodextrins are in agreement with this earlier work. $N$-Acetyl-D-glucosamine was a very poor inhibitor, being 90 -fold less potent than the corresponding disaccharide. The inhibitory power increased with increasing chain length up to the trisaccharide; $N, N, N^{\prime \prime}$-triacetylchitotriose was 6 times more inhibitory than $N, N^{\prime}$-diacetylchitobiose, and $N, N^{\prime}, N^{\prime \prime}, N^{\prime \prime \prime}$-tetraacetylchitotetraose was nearly equivalent to the trisaccharide in inhibitory power, suggesting 
that the carbohydrate-binding site can accommodate three sugar residues.

Reduction of the chitin oligomers with sodium borohydride gave the corresponding alditols, containing one less intact sugar ring than the parent compound. This resulted in the reduction of inhibitory potency to that of the next lower homolog. The reduced disaccharide did not inhibit at the highest concentration tested ( $8 \mathrm{~mm})$, and the reduced trisaccharide was approximately 10-fold poorer than $N, N^{\prime}, N^{\prime \prime}$ triacetylchitotriose, but only 1.7 times poorer than $N, N^{\prime}$-diacetylchitobiose. The reduced tetrasaccharide inhibited to almost the same extent as the parent sugar and was of equal potency to $N, N^{\prime}, N^{\prime \prime}$-triacetylchitotriose. These findings indicate that the open-chain alditol portion of the reduced sugars does not contribute significantly to binding to Datura lectin, and also support the hypothesis that Datura lectin contains three subsites, and thus optimally binds $N, N^{\prime}, N^{\prime \prime}$-triacetylchitotriose.

Comparison of the chitin oligomers with their corresponding methyl $\beta$-glycosides indicated that the methyl group did not influence binding of the sugar by the protein. In contrast, the presence of the aromatic $p$-nitrophenyl aglycone had a marked effect on the inhibitory activity of the saccharides. $p$-Nitrophenyl $\beta$-D-GlcNAc $p$ was 20 times more inhibitory than $N$-acetyl-D-glucosamine. $p$-Nitrophenyl $N, N^{\prime}$-diacetyl- $\beta$-chitobioside was 10 times more potent an inhibitor than $N, N^{\prime}$-diacetylchitobiose, but little enhancement of $p$-nitrophenyl $N, N^{\prime}, N^{\prime \prime}$-triacetyl- $\beta$-chitotrioside relative to the parent sugar was observed. Thus, the $p$-nitrophenyl derivatives of $N, N^{\prime}$-diacetylchitobiose and $N, N^{\prime}, N^{\prime \prime}$ triacetylchitotriose were equally good inhibitors, being equivalent to $N, N^{\prime}, N^{\prime \prime}, N^{\prime \prime \prime}$ tetraacetylchitotetraose. The lack of inhibition by $p$-nitrophenyl $\beta$-D-galactoside indicates the necessity for an $N$-acetyl-Dglucosamine residue.

The inhibitory power of $\beta$-D-Gal- $(1 \rightarrow$ 4)-D-GlcNA.c ( $N$-acetyllactosamine) and $\beta$ $\mathrm{n}$-Man-(1 $\rightarrow$ 4)-D-GlcNAc is particularly noteworthy. Both disaccharides differ from $N, N^{\prime}$-diacetylchitobiose at the $\mathrm{C}-2$ position of the nonreducing sugar, containing an hydroxyl rather than an $N$-acetamido group. The hydroxyl group at $\mathrm{C}-2$ is in the axial position in the mannosyl unit, and in the equatorial position in the galactosyl unit. $N$-Acetyllactosamine further differs from $N, N^{\prime}$-diacetylchitobiose at C-4 of the nonreducing sugar unit. The configuration of the hydroxyl group at C-4 of this inhibitor is axial, whereas it is in the equatorial position in $N, N^{\prime}$,-diacetylchitobiose. The inhibitory power of all three disaccharides, however, was very similar. These results argue against the direct involvement of substituents at C-2 and C-4 of the nonreducing sugar in the binding of these disaccharides to Datura lectin. Considering the presumed specificity of Datura lectin for $\beta-(1 \rightarrow 4)$ linked oligomers of $N$-acetyl$D$-glucosamine, the noninvolvement of the $N$-acetamido group in the nonreducing sugar was rather surprising. That the remaining $N$-acetamido group is important, however, is apparent from the lack of inhibition by cellobiose and by lactose, even at concentrations of $200 \mathrm{~mm}$.

The trisaccharide $\alpha-\mathrm{D}-\mathrm{Man}-(1 \rightarrow 3)-\beta-\mathrm{D}-$ Man- $(1 \rightarrow 4)-D-G l c N A c$ also exhibited the same inhibitory power as $N, N^{\prime}$-diacetylchitobiose. Thus, the presence of a substituent at the 3 position of the nonreducing disaccharide unit does not greatly affect binding, and perhaps even enhances it slightly relative to the parent disaccharide, $\beta$-D-Man- $(1 \rightarrow 4)-D-G l c N A c$. In support of this finding, Pardoe and co-workers (2) have shown that a tetrasaccharide from Micrococcus lysodeikticus containing alternating residues of $N$-acetyl-D-glucosamine and $N$-acetylmuramic acid in $\beta-(1 \rightarrow 4)$ linkage, is a potent inhibitor of hemagglutination by Datura lectin.

The presence of a mannose group at the reducing end of $N$-acetyllactosamine [ $\beta$-DGal-(1 $\rightarrow 4)-\beta$-D-GalNAc- $(1 \rightarrow 6)-D-M a n]$ also did not significantly change its inhibitory power. Inhibitory activity was decreased eightfold, however, if the $N$-acetyllactosamine unit was linked to the C-2 position of mannose, as in $\beta-\mathrm{D}-\mathrm{Gal}-(1 \rightarrow$ 4)- $\beta$-D-GlcNAc- $(1 \rightarrow 2)$-D-Man.

A series of $N, N^{\prime}$-diacetylchitobiose derivatives was prepared in which the $N$-acetamido group of the reducing sugar was 
modified. Replacement of the $N$-acetamido group with an $N$-trifluoroacetamido or an $N$-propionamido group had no effect on the inhibitory potency of the sugar. In contrast, the $N$-benzamido- derivative did not inhibit at the highest concentration tested ( $4 \mathrm{mM}$ ); limited solubility prevented it from being studied at higher concentrations. The 2 -amino-2-deoxy-derivative $(\beta$-D-GleNAc$(1 \rightarrow 4)-D-G l c N)$ was a twofold poorer inhibitor than the parent $N, N^{\prime}$-diacetylchitobiose. However, $\beta$-D-GlcNAc- $(1 \rightarrow 4)$-DGlc was not an inhibitor $(28 \%$ at $50 \mathrm{mM})$, indicating that the $-\mathrm{NH}_{2}$ group at $\mathrm{C}-2$ of the reducing sugar is important in binding. With the exception of the bulky $N$-benzamido derivatives, inhibitory potency is increased when the amino group is present as an amide linkage.

The importance of the acetamido group for binding to Datura lectin was further investigated using disaccharide inhibitors in which both $N$-acetyl groups had been modified. Methyl $N, N^{\prime}$-ditrifluoroacetyl- $\beta$ chitobioside and methyl $N, N^{\prime}$-dipropionyl$\beta$-chitobioside were approximately 3.5 and 4.3 times poorer inhibitors respectively than methyl $N, N^{\prime}$-diacetyl- $\beta$-chitobioside. Chitobiose $(\beta-\mathrm{D}-\mathrm{GIcN}-(1 \rightarrow 4)-\mathrm{D}-\mathrm{GlcN})$, with two free $-\mathrm{NH}_{3}^{+}$groups, was not an inhibitor at the highest concentration tested (12 mM).

Disaccharides containing $\beta-(1 \rightarrow 6)$ linkages were poor inhibitors; $\beta$-D-GlcNAc$(1 \rightarrow 6)$-Gal was equivalent to the monosaccharide $N$-acetyl-D-glucosamine in its ability to inhibit the precipitation reaction. The dissacharide D-Gal- $(1 \rightarrow 6)$-D-GlcNAc did not inhibit at the highest concentration tested $(32 \mathrm{~mm})$. Also noninhibitory were $3,6 \mathrm{di}-O-(\beta-\mathrm{D}-\mathrm{GlcNAc})-\mathrm{D}-\mathrm{Gal} ; 2,6-\mathrm{di}-\alpha-(\beta-\mathrm{D}-$ GleNAc)-D-Man; and $2,4 \mathrm{di}-O-\left(\beta-\mathrm{D}^{-}\right.$ GlcNAc)-D-Man, although shortage of material prevented these trisaccharides from being tested at very high concentrations. The compound $\beta-\mathrm{D}-\mathrm{GlcNAc}-(1 \rightarrow \mathrm{N})$ Asn did not inhibit precipitation at the highest concentration tested (12 mM).

Methyl 3-O-methyl- $\beta$-D-GlcNAc $p$ and 4$O$-methyl-D-GleNAc were equivalent to $N$ acetyl-D-glucosamine in inhibitory potency; at the highest concentration tested (50 $\mathrm{mm}), 16$ and $11 \%$ inhibition, respec- tively, was observed. The lack of inhibition by $4-O$-methyl-GleNAc $p$ is significant. It indicates the necessity for a sugar substituent at the C-4 position of $\mathrm{N}$-acetyl-Dglucosamine.

By far the most potent inhibitors tested were the synthetic oligosaccharides (Fig. 4, Table II), which correspond to portions of the tetraantennary structure of $\mathrm{N}$-acetyllactosamine-type glycoproteins. The best inhibitor was Penta-2,6 (2.5 $\mu \mathrm{M})$, which was 1000 times more potent than $N, N^{\prime}$ diacetylchitobiose, and almost $10^{5}$ times more potent than $N$-acetyl-D-glucosamine. Nona II, a triantennary oligosaccharide not found in nature, and Undeca, a tetraantennary oligosaccharide, were nearly equivalent to Penta-2,6 in inhibitory potency (4.6 and $6.4 \mu \mathrm{M}$, respectively). It is noteworthy that the Penta-2,6 unit is a structural component of both these oligosaccharides (Nona II and Undeca). Penta-2,4, Nona I (which contains a Penta-2,4 group moiety), and Hexa-3,6 were of similar inhibitory potency, and approximately $25-50$ times less potent than Penta-2,6. The heptasaccharide was 180 times less potent as an inhibitor than Penta2,6 , and only 4.4 times more potent than $N, N^{\prime}$-diacetylchitobiose.

\section{DISCUSSION}

We rationalize the results of our hapten inhibition studies between the $D$. stramonium lectin and naturally occurring and chemically modified mono- and oligosaccharides as follows: the binding site of $D$. stramonium is composed of three subsites, designated A, B, and C (Fig. 5), a situation reminiscent of wheat germ agglutimin (28) and the potato lectin $(29,30)$. A disaccharide can potentially bind to the lectin in two ways, occupying subsites $A$ and $B$, or subsites $B$ and $C$. We propose that the minimal requirements for binding include an equatorial acetamido group at C-2 of the sugar occupying subsite $B$; an amino group at $\mathrm{C}-2$ of the sugar greatly diminishes its binding affinity. Additionally, the sugar occupying subsite $B$ must be present in a $\beta-(1 \rightarrow 4)$ linkage. There is considerable freedom in the allowed configuration of the sugar occupying subsite A. An $N$-acet- 


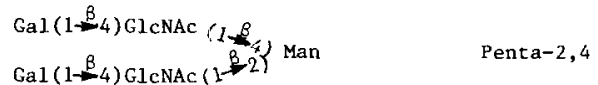

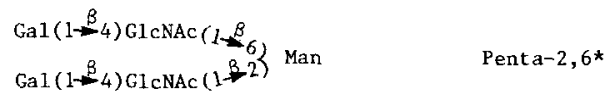

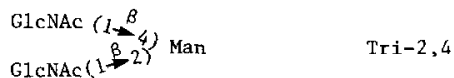

$$
\begin{aligned}
& \begin{array}{l}
\operatorname{GlcNAC}\left(1-\frac{\beta}{6}\right) \\
\operatorname{GlcNAC}(1-2) \operatorname{2an}
\end{array}
\end{aligned}
$$$$
\operatorname{Gal}\left(1+\frac{\beta}{-} 4\right) \operatorname{GlcNAc}\left(1+\frac{\beta}{-\beta}\right) \operatorname{Man}\left(1 \beta_{6}^{\beta}\right) \text { Man Hepta }
$$$$
\operatorname{Gal}(1-4) \operatorname{GlcNAC}(1-2) \operatorname{\beta an}(1-3) \text { Man Hepta }
$$$$
\begin{aligned}
& \operatorname{Gal}\left(1-\frac{\beta}{-4}\right) \operatorname{GlcNAC}\left(1+\frac{\beta}{\beta} 6\right) \operatorname{Man}\left(1-\frac{\alpha}{-} 2\right) \operatorname{Man} \\
& \operatorname{Gal}(1-4) \mathrm{GlcNAC}(1+3)
\end{aligned}
$$$$
\operatorname{Ga1}(1 \rightarrow 4) \operatorname{GlcNAC}\left(1-\frac{B}{4}\right.
$$

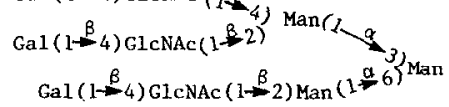$$
\operatorname{Gal}\left(1-\frac{\beta}{-4}\right) \operatorname{GlcNAC}(1-4) \operatorname{Ban}\left(1-\frac{\beta}{-}\right) \text { Man }
$$

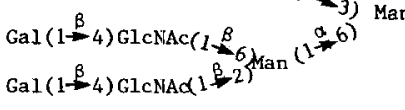

Hexa-3,6

Nona II

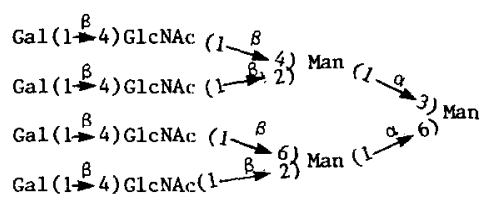

*Aryl Penta-2, 5 has an $\alpha$-linked $\mathrm{E}^{-\mathrm{C}_{6}} \mathrm{H}_{4} \mathrm{NHCOCF}_{3}$ aglycone

FIG. 4. Structures of synthetic oligosaccharides assayed for their ability to inhibit the precipitation reaction between Datura lectin and asialofetuin.

amido group is not necessary for binding to this subsite. Thus, disaccharides containing a single $\beta-(1 \rightarrow 4)$-linked GlcNAc residue in the reducing position, such as $\beta$-D-Gal, Man-(1 $\rightarrow$ 4)-D-GlcNAc, would bind to subsites $A$ and $B$, respectively. The proposed interaction of several sugars with the lectin's subsites is illustrated in Fig. 5.

Although consistent with the hapten inhibition results, this model is obviously limited by the availability of structurally relevant compounds. To further define the important structural features involved in binding site interactions, further oligosaccharides must be tested. For example, all of the sugars tested contained an equatorial hydroxymethyl group at C-6 and an equatorial hydroxyl group at C-4. Modification of these groups would be expected to yield important information about the specificity requirements of the $D$. stramonium binding site.

The nature of the interaction between Datura lectin and the aromatic aglycone portion of a given sugar also remains unclear. Hapten inhibition studies indicated that the $p$-nitrophenyl glycosides of $N$-acetyl-D-glucosamine and its $\beta-(1 \rightarrow 4)$ linked oligomers were potent inhibitors. The in-

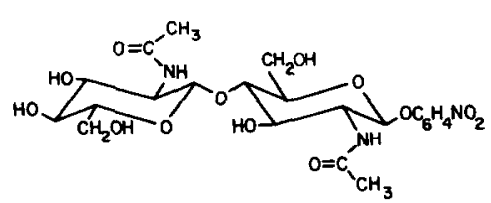

1

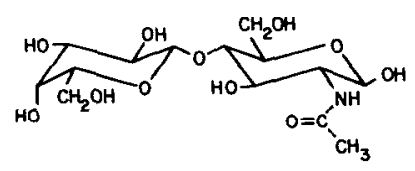

2
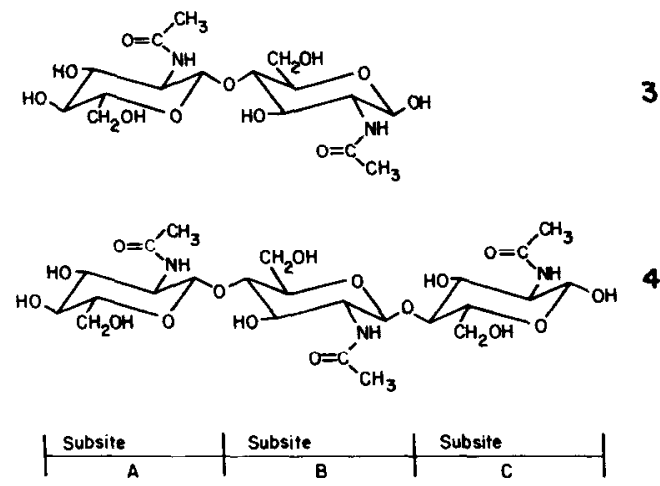

FIG. 5. Proposed three-subsite model of the Datura lectin-binding site indicating the subsites occupied by the indicated sugars: $1, p$-nitrophenyl $N, N^{\prime}$-diacetyl- $\beta$-chitobioside; $2, N$-acetyllactosamine; $3, N, N^{\prime}$-diacetylchitobiose; $4, N, N^{\prime} N^{m}$-triacetylchitotriose. 
hibition was specific, inasmuch as $p$-nitrophenyl $\beta$-D-galactoside was a noninhibitor. In both uv difference spectroscopy and fluorescence spectroscopy, however (Crowley and Goldstein, unpublished results), no specific perturbations of the aglycone could be detected. In addition, no positive peak in the uv difference spectrum at $295 \mathrm{~nm}$ was observed with the $p$-nitrophenyl glycoside, as is seen when free $N, N^{\prime}$-diacetylchitobiose interacts with Datura lectin. We propose that a hydrophobic interaction occurs between the $p$-nitrophenyl aglycone of $N$-acetyl-D-glucosamine and $N, N^{\prime}$-diacetylchitobiose, both of which exhibit enhanced binding compared to their parent sugars, and a region on the Datura lectin between subsites $B$ and $C$. According to this scheme (Fig. 5) the monomer would occupy subsite $B$ and the dimer subsites $A$ and $B$, respectively. This would also account for the fact that both $p$-nitrophenyl $N, N^{\prime}, N^{\prime \prime}$-triacetyl- $\beta$-chitotrioside and $p$ nitrophenyl $\beta$-D-Gal- $(1 \rightarrow 4)-\beta$-D-GleNAc$(1 \rightarrow 2)-\beta$-D-Man $p$, which would occupy subsites A, B and C, showed no enhanced binding.

Additional information about the binding-site specificity of Datura lectin was obtained using a series of branched-chain oligosaccharides as inhibitors. The structures of these oligosaccharides (see Fig. 4) correspond to portions of the tetraantennary structure of $N$-acetyllactosamine-type glycoproteins. The most striking feature of these branched-chain oligosaccharides is their remarkably high inhibitory potency relative to the component $\mathrm{di}$ and tri units $(\beta$-D-Gal- $(1 \rightarrow 4)$-D-GlcNAc, and $\beta$-D-Gal$(1 \rightarrow 4)-\beta$-D-GlcNAc- $(1 \rightarrow 2)$-D-Man; see Tables I, II). Penta-2,6 in particular, as well as Nona II and Undeca, which contain a penta 2,6-moiety, were 2-3 orders of magnitude more potent inhibitors than $N, N^{\prime}$ diacetylchitobiose. Compounds containing a penta-2,4 or hexa-3,6 moiety were $25-50$ times less potent. One explanation for these results is that a biantennary saccharide, such as Penta-2,6, could occupy both binding sites of Datura lectin simultaneously. Because the free energy of binding $(\Delta G)$ values are additive, and exponentially related to the $K_{d}$ (dissociation constant) val- ues, it follows that the simultaneous occupation of both binding sites would result in a large increase in affinity for that oligosaccharide. This hypothesis has also been suggested by Kronis and Carver (31) to account for the difference in binding affinity of WGA for simple sugars compared to glycoconjugates present on cell surfaces. For example, the $K_{d}$ value for the binding of $N, N^{\prime}, N^{\prime \prime}, N^{\prime \prime \prime}$-tetraacetylchitotetritol by Datura lectin, as measured by equilibrium dialysis, is $1.2 \times 10^{-4} \mathrm{M}\left(K_{a}=8.7 \times 10^{3}\right.$ $\mathrm{M}^{-1}$ ). From the hapten inhibition studies reported in this work, it was shown that $N$-acetyllactosamine is about a threefold poorer inhibitor than $N, N^{\prime}, N^{\prime \prime}, N^{\prime \prime \prime}$-tetraacetylchitotetritol. Therefore, the $K_{d}$ for $N$-acetyllactosamine can be roughly approximated to be $4 \times 10^{-4} \mathrm{M}$, which corresponds to a $\Delta G$ value of $-4.7 \mathrm{kcal} / \mathrm{mol}$. The $\Delta G$ for binding two $N$-acetyllactosaminyl units would thus be $-9.3 \mathrm{kcal} / \mathrm{mol}$, which corresponds to a $K_{d}$ value of 1.6 $\times 10^{-7} \mathrm{M}$. (If the $K_{d}$ for a single $N$-acetyllactosaminyl unit was $1 \times 10^{-3} \mathrm{M}$, the $K_{d}$ for two such units would be $1 \times 10^{-6} \mathrm{M}$ ). Thus, the simultaneous occupation of both lectin-binding sites can account for an increased association constant of 2-3 orders of magnitude. Indeed, penta-2,6 is approximately 500 times more potent an inhibitor than $N$-acetyllactosamine. Furthermore, preliminary results obtained by uv difference spectroscopy indicate that the affinity constant for penta-2,6 is $1-2 \times 10^{-6} \mathrm{M}$.

This study confirms our previous report (8) that the $D$. stramonium lectin is unique in binding $\mathrm{N}$-acetyllactosamine with high affinity. Only one other agglutinin, the $\mathrm{D}^{-}$ galactose $/ N$ - acetyl - D - galactosamine binding lectin present in Erythrina crystagalli seeds (32), also interacts strongly with this disaccharide unit. It is indeed interesting that the Datura lectin appears to have the same specificity for the penta2,6 oligosaccharide as leucoagglutinin (LPHA), the $L_{4}$ isolectin of the red kidney bean, Phaseolus vulgaris $(33,34)$. Since $N$ acetyllactosamine is a structural component of many glycoproteins, reactivity with Datura lectin may have important implications regarding the use of Datura lectin as a biochemical tool. 
This study also reports the high-affinity interaction of Datura lectin with several complex oligosaccharides. Preliminary results suggest that these biantennary oligosaccharides bind to both lectin-binding sites simultaneously. This hypothesis is currently being tested in our laboratory.

Note added in proof: Immobilized Datura stramonium lectin has been used to bind poly- $N$-acetyllactosamine-type glycopeptides [Cummings, R. D. and Kornfeld, S. (1984) J. Biol. Chem. 259, 6253-6260].

\section{REFERENCES}

1. Eisler, M., AND Portheim, L. (1908) Z. Immunitaetforsch. Exp. Ther. 1, 151.

2. Pardoe, G. I., Bird, G. W. G., Uhlendruck, G., Sprenger, I., AND Heggen, M. (1970) Z. Immunitaetsforsch. Klin. Immunol. 140, 374-394.

3. KilpatRick, D. C., AND YEOMAN, M. M. (1978) Biochem. J. 175, 1151-1153.

4. Desai, N., Aluen, A. K., AND Neuberger, A. (1981) Biochem. J. 197, 345-353.

5. Yeoman, M. M., KilPatrick, D. C., NiedzyBRODZKA, M. B., AND GoUld, A. R. (1978) Symp. Soc. Exp. Biol. 32, 139-160.

6. KilpatRiCk, D. C., Yeoman, M. M., AND Gould, A. R. (1979) Biochem. J. 184, 215-219.

7. HoREJSI, V., AND KocoureK, J. (1978) Biochim. Biophys. Acta. 532, 92-97.

8. Crowley, J. F., ANd Goldstein, I. J. (1981) FEBS Lett. 130, 149-152.

9. Ashford, I), Desai, N. N., Allen, A. K., NeuBerger, A., O'NeIll, M. A., ANd Selvendran, R. R. (1982) Biochem. J. 201, 199-208.

10. Osawa, T. (1966) Carbohydr. Res. 1, 435-443.

11. BergmanN, M., AND Silberkweit, E. (1931) $\mathrm{Na}$ turwissenschaften 19, 20.

12. Dahlquist, F. W., AND Raftery, M. A. (1969) Biochemistry 8, 713-725.

13. Midoux, P., Grivet, J. P., And Monsigny, M. (1980) FEBS Lett. 120, 29-32.

14. Wolfrom, M. L., AND Conigliaro, P. J. (1969) Proc. Natl. Acad. Sci. USA 11, 63-76.
15. ARnaRP, J., AND Lönngren, J. (1981) J. Chem. Soc. Perkin Trans. 2, 2070-2074.

16. ARnarP, J., HARALdSSON, M., AND LÖNnGREN, J. (1981) Carbohydr. Res. 97, 307-313.

17. ARnARP, J., LönNGREN, J., AND OTTOSSON, H. (1981) Carbohydr. Res. 98, 154-156.

18. Arnarp, J., Haraldsson, M., and Lönngren, J. (1982) J. Chem. Soc. Perkin Trans. 2, 1841-1844.

19. Spiro, R. G., AND Bhoyroo, V. D. (1974) J. Biol. Chem. 249, 5704-5717.

20. WARREN, L. (1959) J. Biol. Chem. 234, 1971-1975.

21. Distler, J. J., and Jourdian, G. W. (1973) J. Biol. Chem. 248, 6772-6780.

22. Finch, P. R., YUen, R., Schachter, H., and MosCAREllo, M. A. (1969) Anal. Biochem. 31, 296302.

23. So, L. L., AND GoldsteIn, I. J. (1967) J. Biol Chem. 242, 1617-1622.

24. ShIER, W. T. (1971) Proc. Natl. Acad. Sci. USA 68, 2078-2082.

25. Hammarström, S., Engvall, E., Johansson, B. G., Svensson, S., Sundblad, G., AND GoldSteIn, I. J. (1975) Proc. Natl. Acad. Sci. USA $72,1528-1532$.

26. LindBerg, B., Lönngren, J., AND Powell, D. A. (1977) Carbohydr. Res. 58, 177-186.

27. Debray, H., Decout, D., Strecker, G., Spik, G., AND Montreuil, J. (1981) Eur. J. Biochem. 117, 41-55.

28. Allen, A. K., Neuberger, A., ANd Sharon, N. (1973) Biochem. J. 131, 155-162.

29. Allen, A. K., AND Neuberger, A. (1973) Biochem. J. 135, 307-314.

30. DelmotTe, F., Kieda, C., ANd Monsigny, M. (1975) FEBS Lett. 53, 324-330.

31. Kronis, K. A., AND CARver, J. P. (1982) Biochemistry 21, 3050-3057.

32. Kaladas, P. M., Kabat, E. A., Iglesias, J. L., Lis, H., AND Sharon, N. (1982) Arch. Biochem. Biophys. 217, 624-637.

33. Cummings, R. D., AND KoRnfeld, S. (1982) J. Biol. Chem. 257, 11230-11234.

34. Hammarström, S., Hammarström, M.-L., SUndBLAD, G., ARNARP, J., AND LöNNGREN, J. (1982) Proc. Natl. Acad. Sci. USA 79, 1611-1615. 